About the Author: Carlos Jesus is a medical student of the Universidad de San Martín de Porres, Chiclayo, Perú. He is also the President of the Scientific Society of Medical Students Veritas (SCIEMVE), Chiclayo, Perú

Submission: Sep 17, 2014 Acceptance: Oct 25, 2014

\section{The Clinical Eye: A Need to Improve the Teaching of Semiology in Undergradua- te Medical Education}

\section{To the Editor,}

Undergraduate medical education is essential for the proper development of professional competencies and skills among medical students. The complexity of today's challenges requires that medical professionals be equipped with the knowledge and skills to address the contingency of diseases, epidemics and disasters currently affecting global public health. Excellent undergraduate medical education and training is necessary to enable the development of future health professionals who are able to provide exceptional medical care.'

Medicine is a combination of science and art. The main objective of a physician is to cure patients, or at least alleviate their symptoms and discomforts, giving them a better quality of life. The first step of the overall medical approach is to make a diagnosis based on clinical signs and symptoms. A correct diagnosis allows for the institution of an appropriate therapeutic approach and a better prognostic evaluation of the diagnosed condition. Thus, it is of grave importance that physicians are well trained in order to avoid incorrect diagnoses which can lead to behaviors or decisions that can potentially endanger a patient's health..$^{2,3}$

Semiology is the art of diagnosis that allows for the development of well-defined skills required for the successful application of the clinical method: communication, detection, interpretation, diagnosis and intervention. It is the branch of medicine devoted to the study of the various pathological manifestations (symptoms and signs), finding them (semiotechnique), grouping them into syndromes and giving the subsequent interpretation (clinical propaedeutics), all of which are crucial to make or guide the disease diagnosis. ${ }^{1,2} \mathrm{~A}$ relevant concept of "clinical eye" is defined as the semiological competence which consists in the use of the senses to make the diagnosis of diseases. While there is no standard model of organized steps, there is a general agreement that the process should start with observation. ${ }^{4}$

Currently, the development of increasingly sophisticated medical technologies is leading to an erroneous thought that semiology is not as useful in medical practice as it used to be, dismissing the training in this field of medicine and shifting the focus to more advanced diagnostic tools. ${ }^{2}$ Consequently, the high sum of money spent on these diagnostic tools, which include newer and more expensive laboratory and radiological tests, has fueled the dramatic increase in health care expenditure over the last few years, especially in western countries. ${ }^{5}$ In addition, preoperative tests are often not utilized in accordance with the clinical criteria. Many of the requested preoperative investigations are unnecessary and have no benefit, resulting in higher costs for the hospital or the patient, congestion in the laboratory department and a high possibility of false positive results. ${ }^{6,7}$

A good semiology can provide accurate diagnosis without additional tests or at least lead to a limited group of differential diagnoses that help in the selection of few very specific tests, reducing the unnecessary ones and the overall cost.? Undergraduate medical education represents the perfect stage to assist and guide the students in the training of their "clinical eye". Regrettably, the teaching of semiology is inadequate in medical schools at present. ${ }^{1,8}$ Furthermore, there is heterogeneity in the techniques used for student training, mainly due to the diverse backgrounds of teachers, high teacher turnover and poor teacher training. ${ }^{8}$

Improving the current situation would require an adequate undergraduate medical education and the implementation of new teaching methodologies. For example, it has been shown that systematic observation of figurative paintings improves medical students' observation skills, where students are more likely to provide a complete and accurate diagnosis of clinical photographs of patients with medical conditions that have clearly observable manifestations. ${ }^{4}$ Additionally, it is important to promote a greater involvement of students in the process of building knowledge through workshops, conferences, case reports, interdisciplinary forums and problem-based learning.8 Another strategy is to put more emphasis on practical training to promote students' direct contact with patients and allow for the familiarization with different illnesses and the practice of the skills of anamnesis. We emphasize that any medical semiology training must define well what findings are normal in a healthy patient. To identify what is abnormal, we must first know what is normal.

In summary, it is important to have the mind well-trained so that "the clinical eye" can give us a good diagnosis. Always remember: the best tools of physicians are their own senses.

\section{Carlos Jesús Toro-Huamanchumo, ${ }^{1,2^{*}}$ Laura Rosa Arce-Villalo- bos. ${ }^{1,2}$ \\ 'Scientific Society of Medical Students Veritas (SCIEMVE). Chiclayo, Perú. ${ }^{2} S c h o o l$ of medicine, Universidad de San Martín de Porres. Chiclayo, Perú. *tor02993@hotmail.com}

\section{Acknowledgments: None.}

Conflict of Interest Statement at Funding: The Authors have no funding, financial relationships or conflicts of interest to disclose.

Author Contributions: Conception and design the work/idea: CJTH. Write the manuscript, Critical revision of the manuscript, Approval of the final version: CJTH, LRAV.

Cite as: Toro-Huamanchumo CJ, Arce-Villalobos LR. The Clinical Eye: A Need to Improve the Teaching of Semiology in Undergraduate Medical Education. Int J Med Students. 2014 Jul-0ct;2(3):144-5.

\section{References}

1. Serra-Valdes MA, Viera-Garcia M. [Considerations on the teaching of Semeiology, Propaedeutics and the diagnostic process in the clinical practice]. Educ Med Super. 2014 Jan-Mar;28(1):163-74. Spanish.

2. Scheen A]. [Medical interviewing, initial key step in the disease diagnosis]. Rev Med Liege. 2013 Nov;68(11):599-603. French.

3. Herrera-Galiano A, Serra-Valdes MA. [The diagnostic process and its teaching in medicine]. Rev Haban Cienc Med. 2011 Mar;10(1):126-34. Spanish. 4. Shapiro J, Rucker L, Beck J. Training the clinical eye and mind: using the arts to develop medical students' observational and pattern recognition skills. Med Educ. 2006 Mar;40(3):263-8. 
5. Vegting IL, van Beneden M, Kramer MH, Thijs A, Kostense PJ, Nanayakkara PW. How to save costs by reducing unnecessary testing: lean thinking in clinical practice. Eur J Intern Med. 2012 Jan;23(1):70-5.

6. Garcia AP, Pastorio KA, Nunes RL, Locks GF, Almeida MC. [Indication of preoperative tests according to clinical criteria: need for supervision]. Braz J Anesthesiol. 2014 Jan-Feb;64(1):54-61. Portuguese.

7. Leon-Jimenez F, Florian-Romero E, Cajan-Lontop Y, Ventura-Sandoval L, Flores-Tucto M, Gastelo-Davila A. [Unnecessary preoperative test and the cost in a hospital of Lambayeque]. Acta Med Per. 2014 Apr;31(2):90-4. Spanish.

8. Midao CM de V, Ruiz-Moreno L. [Teaching the Medical Semiology at medical schools in the State of Rio de Janeiro]. Rev Bras Educ Med. 2010;34(3):397-405. Portuguese. 